\title{
Can A Naturally Ventilated Office outperform A Mixed Mode Office? Pilot Study on Occupants' Comfort
}

\author{
Dr Eziaku O. Rasheed ${ }^{1}$, Prof Hugh Byrd² \\ 1 Massey University, Auckland, New Zealand \\ e.o.rasheed@masey.ac.nz \\ 2 University of Lincoln, Lincoln, United Kingdom \\ h.byrd@lincoln.ac.uk
}

\begin{abstract}
It is established that a mixed mode indoor environment provides the best for occupant comfort by augmenting the passive system with a mechanical system when and where required. However, the recent desperation for near zero energy environments, of which natural ventilation provides, warrants the need to explore the possibility of achieving this without sacrificing occupants' comfort. The purpose of this study was to investigate if a naturally ventilated building can outperform a mixed mode building in providing comfort for occupants. The Building in Use (BUS) questionnaire was used to carry out this survey on occupants' comfort in two office buildings in Auckland, New Zealand. The findings showed that occupants of the naturally ventilated office building were slightly more satisfied and comfortable than their counterparts in the mixed-mode office building for almost all the variables of comfort investigated. Thus, the results indicate that naturally ventilated office spaces can provide more comfort than mixed-mode office spaces, if well-designed. This finding suggests that the use of natural ventilation in office environments by designers and building owners should be encouraged. A limitation of this study is that it was carried out in the winter season. The winter season could have affected the results obtained. Also, the study was carried out on only two office buildings. As such, the results cannot be generalised to all office buildings in New Zealand. More surveys on ventilated systems are required for results to be generalisable.
\end{abstract}

Keywords: Natural Ventilation, Mixed Mode Ventilation, Post Occupancy Evaluation, Occupant Comfort.

\subsection{Introduction}

Mixed-mode buildings have been reported to provide better environmental comfort and occupant satisfaction than naturally ventilated buildings (Brager \& Baker, 2009; Alessi et al., 2014, Rasheed et al., 2017). The basic benefit of mixed-mode ventilation over natural ventilation is the maintenance a satisfactory indoor environment by alternating between and combining natural and mechanical systems (air-conditioners) to avoid the cost, energy penalty and consequential environmental effects of full year-round air conditioning (Brager, 2006). The implication is that air conditioners are used only when the indoor comfort conditions are outside the acceptable range for occupants. According to Ward et al., (2012), whereas naturally ventilated buildings (in most 
cases) offer near zero-energy at the expense of occupant comfort, mixed mode buildings achieve both by combining actual and predicted conditions in a dynamic building model to allow preemptive actions - not just responding to conditions, but actively controlling towards an optimal outcome.

However, buildings are nowadays expected to be more environmentally sustainable - using lesser energy throughout its lifespan and sustaining itself in the event of unfavourable climatic conditions. As pointed out by Kwok and Rajkovich (2010), it is important that we begin to futureproof our buildings with adaptive opportunities for passive, low energy buildings in response to the unprecedented climatic variability presented to us by climate change. As such, there is the desperation for near zero energy indoor environments, of which natural ventilation provides. Studies have shown significant savings in energy use with natural ventilation in cities across the globe. For example, Brittle et al. (2016) found that yearly ventilation and cooling energy savings ranging between $21 \%$ and $39 \%$ could be achieved with natural ventilation in Abu Dhabi. Tong et al., (2016) observed that $8-78 \%$ of the cooling energy consumption could be potentially reduced by natural ventilation depending on local weather and air quality. The authors estimated the natural ventilation potential of all the major Chinese cities. Cardinale et al., (2003) showed potentialities of natural ventilation in the reduction of cooling loads and energy consumptions need for the summer in Italy. Tong et al., (2017) estimated 7258 NV potential hours annually at ground level for Los Angeles.

Naturally ventilated spaces depend on passive strategies for heating, cooling and the ventilation of the indoor environment. Based on the adaptive models of comfort (Nicol \& Humphreys, 2010), naturally ventilated spaces allow for wider range of comfort temperature that is more compatible with outdoor conditions. This is because it depends on factors such as the pressure differences that are generated by the effects of wind (speed and direction), indoor and outdoor temperature and a combination of both across the façade openings to achieve thermal comfort. They also require high thermal mass to retain the heat and an appropriate ventilation system that is wellsuited to the overall building design.

Despite the potential to achieve net-zero energy indoor environments, naturally ventilated office spaces are often not the preferred ventilation option amongst designers for office spaces. For instance in New Zealand, they have been shown to be unpopular when compared with mixed mode and air-conditioned buildings (Rasheed et al., 2017; Byrd, 2012). Buildings within Auckland, New Zealand are likely to obtain air conditioning systems of some sort to achieve the required occupants' comfort (Russell and Ingham, 2010). A study carried out by Rasheed et al., (2017) showed that even though they took less sick leaves per year, office workers in New Zealand, preferred working in Mixed-mode office buildings to naturally ventilated office buildings.

As such, this paper investigates whether naturally ventilated office spaces can provide more comfort than mixed mode ventilated office spaces. Based on the findings of Rasheed et al., (2017) that occupants have less sick leaves in naturally ventilated office spaces, the study reported in this paper is a step towards exploring the possibility of achieving environmental sustainability without sacrificing occupants' comfort in naturally ventilated buildings. It aims at 
identifying perceived comfort differences across a range of variables such as lighting, noise and temperature between naturally ventilation and mixed-mode ventilation systems. 


\subsection{Method}

This pilot study contributes to a rich narrative of building performance by employing a postoccupancy evaluation framework. Post-occupancy evaluation (POE) is the process of evaluating buildings in a systematic and rigorous manner after they have been built and occupied for some time (Preiser, Rabonowitz, \& White, 1988). Its major focus is on the needs of the occupants and how the study building is satisfying those needs. From its inception, POE has provided significant information on the performance of buildings, providing information from occupants on how buildings function and how they can be improved to cater to present and future occupants. This is true for any ventilation system as its success depends extensively on the results of POE that depict the ability to provide comfort and environmental satisfaction for occupants especially in commercial buildings. The results presented in this paper highlight the importance of appropriate environmental design to achieving environmental sustainability and occupant comfort.

The study buildings are located in Auckland, New Zealand - a temperature climate characterised by warm summers and not so cold winters. The aim of selecting buildings within the same location is to provide a common basis for comparison between buildings. As it is only a pilot study, two buildings were investigated consisting of a naturally ventilated building (Building A), and a mixed-mode ventilated office building (Building B). It is expected that the findings will lead on to a main study comprising of more office buildings. The sample population included all the occupants of the two office buildings. The identity of the sample buildings had to be kept secret for ethical reasons. To gain sufficient information about both buildings' environmental control systems, interviews with the buildings' managers, site visits and review of project information were carried out.

The Building in Use Studies (BUS) questionnaire was used to survey the building occupants. This questionnaire is a self-reporting method of POE which captures the perceptions of occupants on the conditions of their workspace. This questionnaire is a popular method, and its results have been used extensively in this area of research (Paevere \& Brown, 2008; Baird, 2010; Thomas, 2010; Lenior et al., 2012 etc.). The questionnaire contains questions which are concerned with office environmental performance and operational matters. It uses a structured Likert scale of 1-7 over 45 key variables evaluated in the questionnaire. For both buildings, the questionnaires were administered by hand on the first day of the survey week (Monday). The collection of filled out questionnaires was carried out in the afternoons and took between two and three days of the week following the requirements of the questionnaire licence

\subsection{Findings}

This section provides the results of the questionnaire survey as analysed by the licensing company - BUS Ltd. 
Building $A$ is a series of sub-let speculative offices providing no heating or cooling. Building $B$ is owner-occupied with heating/cooling system provided. As a naturally ventilated buildings, Building A has openable windows with smaller upper windows on each side elevation intended for nighttime cooling. Their use is solely dependent on occupants awareness. Being largely open-plan spaces, it enables cross-ventilation across the indoor space. It was noted that some occupants seated away from the openings in the offices had some small fans on their work desks etc. They acknowledged that the fans were rarely used for circulation. Building $B$ has a mixed mode ventilation system with Low $E$ laminated double glazing employed in the facades. The benefits of low $E$ glass are potential energy efficiency and comfort by transmission of visible light into the offices while blocking heat transfer (Green Consumer Guide.com, 2013). Laminated double glazing should be effective in reducing noise (i.e. providing sound insulation) and heat transmission (thermal insulation and the reduction of solar heat gains) (Metro Glasstech, 2013). Table 1 below shows the characteristics of the surveyed buildings.

Table 1: Building characteristics of the study buildings.

\begin{tabular}{|c|c|c|}
\hline Building Properties & Building A & Building B \\
\hline Year of completion & 2009 & 2008 \\
\hline Size & $9,600 \mathrm{~m}^{2}$ & $60,000 \mathrm{~m}^{2}$ \\
\hline No. of floors & Five (5) & Eleven (11) \\
\hline Type of spaces & Office spaces & $\begin{array}{l}\text { Office spaces, Training rooms, Cafeteria, } \\
\text { Banking facility }\end{array}$ \\
\hline $\begin{array}{l}\text { Air-conditioning } \\
\text { system }\end{array}$ & 100\% Natural (Passive) & $\begin{array}{l}\text { Mixed mode with sun-shading to contro } \\
\text { heat gain. }\end{array}$ \\
\hline Glazing system & About $50 \%$ & Extensive (about 80\%) \\
\hline Sample Population & $\begin{array}{l}\text { All occupants ( } 75 \% \text { of } \\
\text { responses received) }\end{array}$ & $\begin{array}{l}\text { All occupants (58\% of responses } \\
\text { received) }\end{array}$ \\
\hline
\end{tabular}

\subsection{Background information}

Background statistical information on the respondents is given in Table 2. The New Zealand BUS benchmark was used as a comparison. The position of the study building amongst all studied buildings in New Zealand is represented by a building percentile. This shows how well the building has performed in comparison with other buildings that have been studied.

It is worth mentioning here that the NZ BUS benchmarks used for the study buildings are different. Both the buildings were surveyed during the winter season (1 month apart), but the results of the two buildings were processed at different times (5 months apart). As such, different BUS benchmarks were produced for the study buildings. This development was expected as there might have been more buildings surveyed; thus the difference in benchmarks. However, it 
does not affect the results of the comparison carried out on the study buildings significantly because the buildings were compared based on their respective benchmarks and response rates. The background information on data gathered is shown in the table below.

Table 2: Background of respondents for Building $A$ and $B$

\begin{tabular}{lll}
\hline & Building A & Building B \\
\hline Response & $75 \%$ & Background \\
Sex & $60 \%$ (male) & $58 \%$ \\
Normal work base & $99 \%$ & $38 \%$ (male) \\
Worked in building & $46 \%$ (a year or more) & $76 \%$ \\
Window seat & $57 \%$ & $71 \%$ (a year or more) \\
Occupation & Designers, Music producers etc. & $82 \%$ \\
No of Occupants & 87 & Researchers, Bankers etc. \\
\hline
\end{tabular}

\subsection{The occupants' perception of the IEQ factors in their workplace}

\subsubsection{Temperature and Air quality}

Table 3 below shows the satisfaction ratings for Temperature and Air Quality in the sample buildings. For Building A, the occupants were highly satisfied with the temperature and air quality in summer. However, the satisfaction rating for temperature and air in winter was low. The temperature in summer was observed as neither cold nor hot and varied during the day, while the temperature in winter was regarded as cold and also varied during the day. The air in summer was noted as neither dry nor humid and mostly fresh and odourless. The air in winter was regarded as dry, fresh and odourless. Concerning the NZ benchmark, the building performed below the benchmark for air quality and temperature in winter but above the benchmark for air quality and temperature in summer.

In the case of Building B, the temperature in winter and summer were rated as comfortable. The air in winter was perceived as satisfactory, but the perception on air in summer was divided; half of the occupants (50\%) were satisfied with the air quality. The temperature in summer was observed as mostly hot and varied during the day. The temperature in winter was rated as cold and also varied during the day. The air in summer and winter were noted to be mostly still, dry, stuffy and odourless. In respect to the NZ benchmark, the building performed above the benchmark for air quality in winter and temperature in summer and winter but below the benchmark for air quality in summer only. 
Table 3: Mean Satisfaction ratings on Temperature and Air quality (overall) in Buildings $A$ and $\mathrm{B}$

\begin{tabular}{lll}
\hline & Building A & Building B \\
\hline Air Quality in Summer & $\mathbf{4 . 9 7}(67 \%$ satisfied $)$ & $\mathbf{4 . 2 7}(50 \%$ satisfied $)$ \\
Air Quality in Winter & $\mathbf{3 . 7}$ (26\% satisfied) & $\mathbf{4 . 6 4}(64 \%$ satisfied $)$ \\
Temperature in Summer & $\mathbf{5 . 2 1}(69 \%$ comfortable $)$ & $\mathbf{4 . 0 5}(59 \%$ comfortable $)$ \\
Temperature in Winter & $\mathbf{3 . 3 5}(24 \%$ comfortable $)$ & $\mathbf{4 . 6 4}(63 \%$ comfortable $)$ \\
\hline
\end{tabular}

\subsubsection{Noise}

Building $\mathrm{A}$ received a commendable satisfaction rate as $71 \%$ of the respondents were satisfied with the overall noise level. The noise from colleagues and noise from inside the office were regarded as normal, and there were few or no unwanted interruptions. The respondents also noted that the noise from outside was a bit higher than normal. This is expected considering that the building is located on one of the busiest streets of Auckland and is naturally ventilated, requiring operable windows for air flow. Despite this, the building scored higher than the NZ benchmark.

In Building B, 55\% of the respondents were satisfied with the overall noise level. There was also dissatisfaction with the noise from inside the building, noise from other people as well as unwanted interruptions. The noise from colleagues and noise from the outside were regarded as normal. This is expected considering that the building has a greater population. However, as this building is designed to house offices, proper articulation of zones in the building could have mitigated the noise in this case. Despite this, the building scored slightly higher than the NZ benchmark.

The comments on noise in the respondents' work areas from the respondents in Building A were mostly negative, centering on the noise generated from outside the building. Responses like "very noisy when front sliders are open", "traffic outside sirens", "can hear much noise if people outside tenancy are talking" were prevalent. Other responses like "it can be noisy depending on the number of people; open plan office", "reverberation on hard surfaces" identified other sources of noise in the building. In the case of Building B, the comments no Noise were also mostly negative. Responses like "can hear voices, phones in adjoining offices quite clearly. Discussions on social bridge area carry clearly to my office", "high noise level from ground floor", "partitions do not stop noise from adjoining offices particularly telephone cables" were prevalent. Other responses like "I like noisy places", "There is a lot of ambient noise in the building, but it can usually be occluded or ignored" indicated the high noise level in the building. 
Table 4: Satisfaction ratings on Noise in Buildings $A$ and $B(\%)$

Building $\mathrm{A}$

Noise overall

Negatives
$71 \%$ comfortable

Noise from outside
Building $\mathrm{B}$

$55 \%$ comfortable

Noise from inside the building, other people and unwanted interruptions

\subsubsection{Lighting}

The majority of the respondents in Building A perceived that the overall lighting condition in this building as satisfactory (81\%). Artificial lighting was perceived to be satisfactory while natural lighting had some associated problems for many of the respondents. Glare from the sun and sky was also perceived as somewhat high, whereas glare from lighting was perceived as minimal. Overall, the building performed above the NZ benchmark.

In Building B, the overall perception of the occupants was satisfactory (83\%). Both the artificial and natural sources of lighting were rated as normal, and there was little or no glare from lights, sun and sky. This is quite commendable considering that the building is $80 \%$ glazed. However, a later study for this research on the use of blinds and lights on this building showed that the blinds are almost always drawn all year round and artificial lights are constantly switched on during work time. While this measure might have resulted in the occupants viewing the lighting as highly satisfactory, it raises concerns over the effect of this on the energy consumption and usage of the building. The building scored higher than the NZ benchmark for all aspects of lighting.

Responses to the quality of lighting in Building A were mixed. While the respondents complained of glare from sun and sky, there were also mentions of a good mix of artificial and natural lighting. The lighting was perceived to be satisfactory except glare from sun and sky. However, the respondents complained that the toilets were too dark, which could be a result of the colour of the interior walls. Responses in Building B on the quality of lighting contradicted the satisfaction rating obtained. All the answers given by the respondents were negative. The complaints included: "blinds need to be closed most of the year"; "the blinds need to block more light"; "impossible to dim or alter lighting", many areas are too bright"; "prefer not to have two tubes per light fitting in my office - too much". A respondent noted that the glass panels which are intended to block the light seemed ineffective.

प Table 5: Satisfaction ratings on Lighting in Buildings $A$ and $B(\%)$

Building A

Lighting overall

$81 \%$ comfortable

Negative
Glare
Building $B$

83\% comfortable

Glare, Artificial lighting 


\subsubsection{Personal control}

The occupants of Building A acknowledged the importance of having control over the IEQ factors in their building. Some of the respondents stated that they had no control over cooling $(26 \%)$, heating $(23 \%)$ and noise $(25 \%)$ in their workplace resulting in the low percentage of satisfaction rating. This result is interesting as one of the reported benefits of naturally ventilated spaces is that occupants have control over the environmental factors in their workspace by opening windows etc. (Lee and Brand, 2010). On the other hand, a substantial number of the respondents acknowledged that they had partial or full control over noise (29\%), lighting (22\%) and ventilation (21\%). Despite the difference in perception, the study building scored higher than the NZ benchmark in all aspects of control.

The occupants of Building B also acknowledged the importance of having control over the IEQ factors in the building. The occupants rated control over cooling and heating in the building to be poor as the majority rated that they have no control over cooling (74\%), heating (74\%), lighting (24\%), ventilation (52\%) and noise (49\%). Some occupants acknowledged partial control over lighting (21\%). This result relates significantly to the occupants' dissatisfaction with the temperature and noise in the building.

From the figure below, it can be deduced that occupants of building $A$ had more control over the environmental factors in their workplace than occupants of building $B$. 

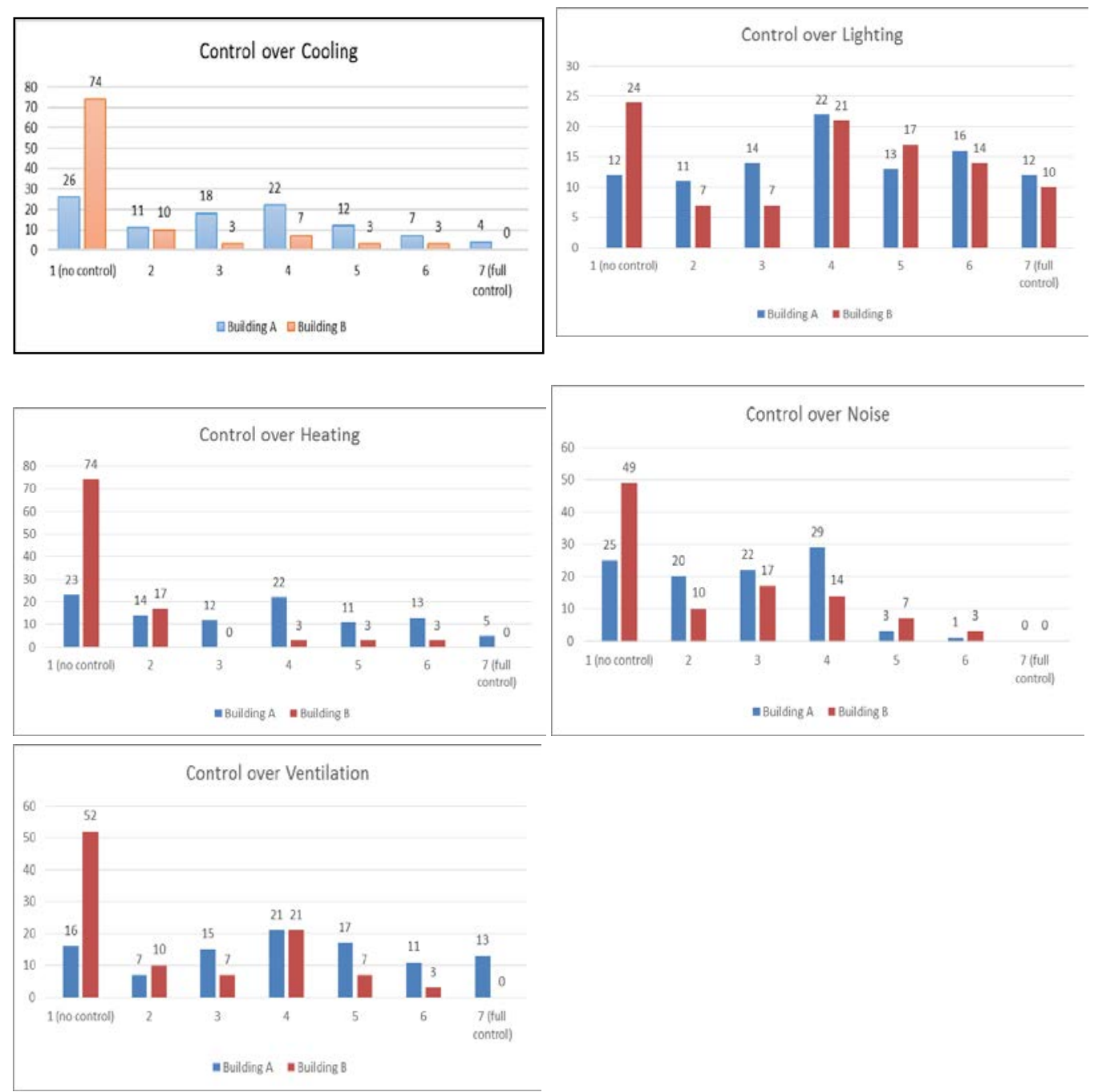

Figure 1: Satisfaction ratings on personal control in Buildings A and B (\%)

\subsubsection{Health}

The majority of the respondents in Building A stated that they did not feel less nor healthier in the building (52\%), 37\% felt they were healthier, while 14\% stated that they were less healthy in the building. This gave the building a percentile of 90 amongst buildings in New Zealand. In Building B, fifty-two percent (52\%) of the respondents stated that they were more healthy; $17 \%$ stated otherwise, and $31 \%$ stated that they were neither less nor more healthy in the building. This gives the building a percentile of 94 amongst buildings in New Zealand, scoring higher than the NZ benchmark.

Responses to health in Building A were mostly positive. However, the quality of these responses described the preference of occupants in relation to previous buildings. The responses were concerned with comfort and did not illustrate or give an indication of the perceived health 
impact of the IEQ in the building on the occupants. As most of the respondents chose neutral as a response to the question whether they felt more or less healthy in the building, the responses were either complimentary or addressed other issues. The reason for this might be as a result of an inability to state or even evaluate an increase or reduction in health in the absence of potential negative effects, i.e. it is not possible to say whether one feels healthier or not, except if the occupants are ill. In the case of Building B, the responses on health were mostly negative in contrast to the positive rating ( $52 \%$ more healthy). The respondents complained of fumes that travel through air-conditioning, sore throat, headaches from glare and the stuffy environment.

Table 6: Satisfaction ratings on Health in Buildings $A$ and $B(\%)$ Building A Building $B$

$52 \%$ - more healthy

\subsubsection{Comfort overall}

Sixty-nine percent $69 \%$ of the occupants rated Building $A$ as comfortable. This building scored higher than the NZ benchmark. Building B was also rated as quite satisfactory $(79 \%)$ in terms of overall comfort. The building scored higher than the NZ benchmark. This result contradicts the numerous complaints by the respondents about the building.

Responses on the overall comfort in Building A were mixed. While some respondents termed the building as "a pleasant environment", "perfectly fine balance" etc., others complained about the temperature of the building during winter. One response stated that the building would be the best building in New Zealand if the temperature issue were worked out. The building was regarded as satisfactory. The responses in Building B were mostly negative. The respondents made responses like "too hot all year round as no air comes through air vents; totally useless airconditioning"; "Would prefer not to have glass panels near doors unobstructed. Do not need to be constantly exposed"; "temperature reduces the overall rating here as it is never right, its either too hot or too cold and we have no real control over our situation". The satisfaction ratings of the factors evaluated in both buildings are presented below.

Table 7: Satisfaction ratings of the factors evaluated in the study buildings (Amber = same as the NZ BUS benchmark; Green = better than the NZ BUS benchmark; Red = worse than the NZ BUS benchmark)

\begin{tabular}{|c|c|c|c|c|c|c|c|c|c|}
\hline & \multicolumn{5}{|c|}{ Building $\mathrm{A}$} & \multicolumn{4}{|c|}{ Building B } \\
\hline \multirow{3}{*}{$\begin{array}{l}\text { Building } \\
\text { Design } \\
\text { Temperature } \\
\text { in Summer } \\
\text { Temperature } \\
\text { in Winter }\end{array}$} & Unsatisactory:1 & Design & & $\phi$ & 7: Satisfactory & Unsatisfactory:1 & Design & & 7: Satisfacto \\
\hline & Uncommortable: 1 & Toverer & & $\phi$ & 7: Comfortalle & Uncomfortable :1 & Tsover & $\phi$ & 7: com \\
\hline & Uncommortable:1 & Twover & $>$ & & 7: Comfortalle & Uncomfortable: :1 & Twover & $\phi$ & 7: Comfo \\
\hline
\end{tabular}




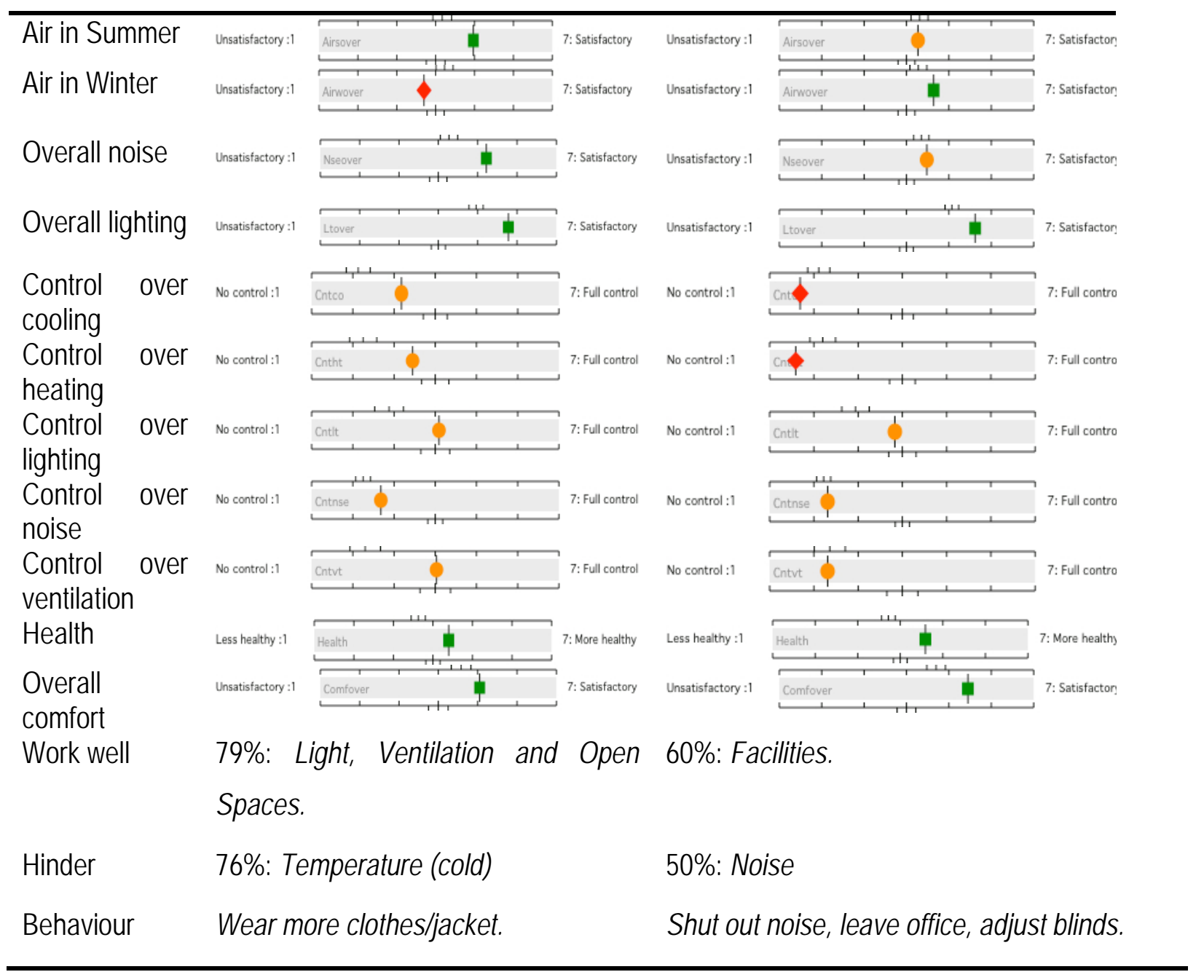

Table 7 above shows a summary of how the buildings performed in relation to the NZ BUS benchmark for the IEQ variables investigated. From the table, it can be deduced the naturally ventilated building (Building $A$ ) performed better than the mixed-mode building (Building $B$ ). It is also interesting to note that ventilation was identified as one of the aspects of the naturally ventilated building that works well to the satisfaction of the occupants.

\section{Discussion}

This survey showed that in comparative terms, the occupants of Building A were slightly more satisfied and comfortable than their counterparts in Building B. The occupants were satisfied with the overall comfort in the building. They were also satisfied with the lighting and noise levels in the building. About temperature and air quality, the occupants were highly satisfied with the temperature and air quality in summer (mean rating $=5.21 ; 4.97$ respectively); they stated that 
the building was pleasant during the summer period of the year. This finding supports those of Honnekeri et al. (2014) who found that occupants in the naturally ventilated zone of a mixedmode building were satisfied in a warmer comfort temperature range. The researchers also found that the opportunity to adapt to the warmer environments in the NV zone by use of windows, fan, blinds and doors overrides the possible increase in thermal expectation from intermittent exposure to the AC zone. The investigations of Daghigh et al. (2008) also support the findings of our study. The researchers found that in a naturally ventilated office, the subjective survey showed that occupants found the conditions to be comfortable.

However, the temperature and air in winter did not meet the expectation of occupants of the Building A (mean rating $=3.35 ; 3.7$ respectively). They noted that they were too cold in the winter. This could have something to do with the fact that the survey was carried out in winter, which could have influenced the occupants' perceptions. This is attributable to the passive measures of indoor environment control employed in the building. There are no major means of heating the building during winter except for the personal heaters used by the occupants. It was noted that the heating systems found in the offices were installed by the occupants and varied considerably.

In the case of Building B, the occupants did not perceive the IEQ as positively, even though they were satisfied with the overall comfort in the building. Although the occupants rated to be reasonably satisfied with the overall temperature and air quality in the building, there were more complaints than praise about the temperature and air quality. Some occupants complained that the building was too hot and stuffy for most of the year. This may be because the thermal control/ventilation system employed in this building was not performing to the satisfaction of the occupants. It was noted that most of the occupants' workstations are located next to a window, and the building is extensively glazed. These could explain the heat gain, and thermal discomfort as most of the windows are not operable windows but instead glazed facades. Also, a significant number of offices are located in-between corridors and do not have direct access to the exterior.

The occupants in Building A were more comfortable with the noise in their building (71\%) than occupants in Building B for Noise (55\%). Regarding complaints, noise in the building B received the highest number of complaints. The occupants raised issues over noise in the foyer, corridors and social bridges. Also, occupants in Building $A$ had more personal control over the indoor environmental factors than the occupants in Building $B$.

\section{Conclusion}

This study investigated the differences in perception of occupants' comfort between a naturally ventilated building and a mixed mode building in New Zealand. The aim was to establish if natural ventilation can provide better comfort than mixed-mode ventilation for occupants in office environments. The data produced diverse findings. Both sample buildings were perceived as satisfactory and comfortable to the occupants, and they performed above the NZ BUS benchmark. Occupants of the naturally ventilated office building were slightly more satisfied and comfortable than their counterparts in the mixed-mode office building. The findings of this study show that naturally ventilated office spaces can provide more comfort than mixed mode office 
spaces if well-designed. This study carried out in the winter season, and this could have affected the results gotten. Also, the results are drawn from a pilot study carried out on only two buildings. More surveys on naturally ventilated buildings and other ventilated systems are required for results to be generalised across New Zealand.

The paper calls for further debate on the employment of natural ventilation in office environments. The reasons why it is not popular amongst office buildings should be investigated.

\section{Acknowledgements}

We will like to acknowledge BUS Ltd for the permission to use the BUS questionnaire and analysing the data collected.

\section{References}

Alessi, A., Heywood, C. and Drake, S. (2014) The office users' experience of mixed-mode systems: Behavioural thermoregulation. In Proceedings of the CIB Facilities Management Conference 2014, Lyngby, Denmark, 21-23 May 2014; pp. 167-178.

Baird, G. (2010). Sustainable Buildings in Practice: What the Users think: Routledge Taylor \& Francis Group, 2 Park Square, Milton Park, Abingdon, Oxon OX14 4RN.

Brager, G.S. (2006) Mixed-mode cooling. ASHRAE Journal, 48(August), 30-37.

Brager G. and Baker L. (2009): Occupant satisfaction in mixed-mode buildings, Building Research \& Information, 37:4, 369-380.

Brittle, J.; Eftekhari, M.; Firth, S. (2016) Mechanical ventilation \& cooling energy versus thermal comfort: A study of mixed mode office building performance in Abu Dhabi. In Proceedings of the 9th Windsor Conference: Making Comfort Relevant Cumberland Lodge, Windsor, UK, 710 April 2016.

Byrd, H. (2012) Energy Climate Building: An Introduction to Designing Future-Proof Buildings in New Zealand and the Tropical Pacific; University of Auckland-Transforming Cities: Auckland, New Zealand, 2012.

Cardinale N., Micucci M. and Ruggiero F. (2003) Analysis of energy saving using natural ventilation in a traditional Italian building. Energy and Buildings 35, 153 -159.

Daghigh, R., Sopian, K. and Sahari, B.A. (2008) Thermal comfort levels investigation of a Naturally Ventilated and Air-conditioned office. In Proceedings of the 8th WSEAS International Conference on SIMULATION, MODELLING and OPTIMIZATION (SMO '08) Santander, Cantabria, Spain, 23-25 September 2008.

Green Consumer Guide.com, (2013). Door and Windows: Low-E-Glass. Accessed 14/03/2018 from: $\quad$ http://www.Greenconsumerguide.com/domesticll.php?CLASSIFICATION=25\&P RENT $=19$.

Honnekeri, A., Brager, G., Dhaka, S. and Mathur, J. (2014) Comfort and adaptation in mixedmode buildings in a hot-dry climate. In Proceedings of the 8th Windsor Conference, London, UK, 10-13 April 2014. 
Kwok, A.; Rajkovich, N. (2010) Addressing climate change in comfort standards. Build. Environ., $45,18-22$.

Lee, S., \& Brand, J. (2010). Can personal control over the physical environment ease distractions in office workplaces? Ergonomics, 53(3), 324-335. doi:10.1080/00140130903389019.

Lenoir, A., Baird, G. \& Garde, F. (2012). Post-occupancy evaluation and experimental feedback of a net zero-energy building in a tropical climate. Architectural Science Review, 55(3), 156168. doi:10.1080/00038628.2012.702449.

McCunn, L. \& Gifford, R. (2012). Do Green offices affect employee engagement and environmental attitudes? Architectural Science Review, 55(2), 128-134. doi:10.1080/00038628.2012.667939.

Metro Glasstech (2013). Laminated: Sound Control. Accessed 14/03/2018 from

http://www.metroglasstech.co.nz/products/safety-glass/laminated.aspx.

Nicol, J. F., \& Humphreys, M. A. (2010). Derivation of the adaptive equations for thermal comfort in free-running buildings in European standard EN15251. Building and Environment, 45, 11 17. doi:10.1016/j.buildenv.2008.12. 013

Paevere, P., \& Brown, S. (2008). Indoor Environment Quality and Occupant Productivity in the CH2 Building: Post-Occupancy Summary. PO Box 56, Highett, VIC, 3190: CSIRO.

Preiser, W., Rabonowitz, H., White E. (1988). Post-occupancy Evaluation. Van Nostrand Reinhold Company, New York.

Rasheed, E.O., Byrd, H., Money, B., Mbachu, J. and Egbelakin, T. (2017) Why Are Naturally Ventilated Office Spaces Not Popular in New Zealand? Sustainability 2017, 9, 902.

Russell, A.P. and Ingham, J.M. (2010) Prevalence of New Zealand's unreinforced masonry buildings. Bull. N. Z. Soc. Earthq. Eng. 2010, 43, 182.

Thomas, L. (2010). Evaluating design strategies, performance and occupant satisfaction: a low carbon office refurbishment. Building Research \& Information, 38(6), 610-624. doi:10.1080/09613218.2010.501654.

Tong Z., Chen Y., and Malkawi A. (2016) Estimating natural ventilation potential for high-rise buildings considering boundary layer meteorology. Applied Energy 19, 276-286.

Tong Z., Chen Y., and Malkawi A., Liu Z. and Freeman R. (2017). Energy saving potential of natural ventilation in China: The impact of ambient air pollution. Applied Energy 179, 660 668.

Ward, J. K., Wal,I J. \& Perfumo, C. (2012) Environmentally active buildings: the controls challenge, Architectural Science Review, 55:1, 26-34. 